Finance and Economics Discussion Series Divisions of Research \& Statistics and Monetary Affairs Federal Reserve Board, Washington, D.C.

\title{
The Long-Run Relationship between House Prices and Rents
}

\section{Joshua Gallin}

2004-50

NOTE: Staff working papers in the Finance and Economics Discussion Series (FEDS) are preliminary materials circulated to stimulate discussion and critical comment. The analysis and conclusions set forth are those of the authors and do not indicate concurrence by other members of the research staff or the Board of Governors.

References in publications to the Finance and Economics Discussion Series (other than acknowledgement) should be cleared with the author(s) to protect the tentative character of these papers. 


\title{
The Long-Run Relationship between House Prices and Rents
}

\author{
Joshua Gallin, Federal Reserve Board *
}

September 2004

\begin{abstract}
I show that when house prices are high relative to rents (that is, when the rent-price ratio is low) changes in real rents tend to be larger than usual and changes in real prices tend to be smaller than usual. Standard error-correction models provide inconclusive results about the predictive power of the rent-price ratio at a quarterly frequency. I use a long-horizon regression approach to show that the rent-price ratio helps predict changes in real rents and real prices over three-year periods. This result withstands the inclusion of a measure of the user cost of capital. I show that a longhorizon regression approach can yield biased estimates of the degree of error correction if prices have a unit root but do not follow a random walk. I construct bootstrap distributions to conduct appropriate inference in the presence of this bias. The results lend empirical support to the view that the rent-price ratio is an indicator of valuation in the housing market.
\end{abstract}

${ }^{*}$ Thanks to Amy Crews-Cutts, Douglas W. Elmendorf, Gregg Forte, Norman Morin, Stephen D. Oliner, Jeremy Rudd, Charles S. Struckmeyer, and William L. Wascher. The views presented are solely those of the author and do not represent those of the Federal Reserve Board or its staff. Please do not cite without the author's permission. 


\section{Introduction}

Nominal house prices in the United States have risen by about 70 percent since 1994. Over the same period, the indexes for tenants' and owners' equivalent rent in the consumer price index have increased less than half as much. ${ }^{1}$ The resulting high level of house prices relative to rents has raised concerns that housing is overvalued.

Such concerns are based on the idea that rents are a fundamental determinant of the value of housing and as such should not move too far out of line with prices. The analogy to the stock market is straightforward: The rent-price ratio in the housing market is like the dividend-price ratio in the stock market (Leamer, 2002). Campbell and Shiller (2001) showed that when stock prices have been high relative to dividends, future price growth for stocks has been subdued. One might reasonably expect the analogous statement to be true for the housing market.

I examined the time-series relationship between house prices and rents from 1970:Q1 to 2003:Q4, using both standard error-correction models and longhorizon regression models to examine how well the rent-price ratio predicts future changes in real rents and prices; the rent-price ratio must have predictive power for house prices for it to be a useful measure of valuation in the housing market. Although the results from a standard error-correction model suggests that rents and prices correct back toward each other, the point estimates are imprecisely estimated, and the results are therefore inconclusive.

My long-horizon approach is quite similar to the one Campbell and Shiller (2001) used to study how well the dividend-price ratio helps predict changes in stock prices and dividends and to the one Mark (1995) used to study exchange rates. I show that if prices follow a general unit root as opposed to a strict random walk (with or without drift), long-horizon regression coefficients will yield biased estimates of the degree of error-correction; Mark's (1995) and Campbell's and Shiller's (2001) approaches do not allow for this possibility. I use a bootstrap approach to adjust for the bias induced by serially correlated shocks to price changes.

\footnotetext{
${ }^{1}$ Except as noted, I use Freddie Mac's Conventional Mortgage House Price index to measure house prices, the tenants' rent series from the consumer price index to measure rents, and the price deflator for personal consumption expenditures excluding food and energy to deflate nominal values.
} 
My main findings are that periods in which house prices are high relative to rents appear to be followed by periods in which real rent growth is faster than usual, and real house-price growth is slower than usual, and that the response of prices dominates that of rents. I show that it can be difficult to compare the long-horizon results to those from a standard error-correction model because the signs and magnitudes of the estimated coefficients on the rent-price ratio in a long-horizon regression can yield biased estimates of the degree of errorcorrection. I use a bootstrap approach to correct for such biases and show that we can reject the null hypothesis that rents "do all the correcting." In other words, the view that a low rent-price ratio indicates that house prices could be too high appears to have some empirical basis. Including a measure of the user cost of housing capital does not alter the result.

\section{A brief review of the theory and existing lit- erature}

In the standard textbook model of house prices and rents in a frictionless market, rent should cover the user cost of housing:

$$
R_{t}=P_{t}\left[\left(i_{t}+\tau_{t}^{p}\right)\left(1-\tau_{t}^{y}\right)+\delta_{t}+\lambda_{t}-E_{t} G_{t+1}\right]
$$

where $i_{t}$ is the real interest rate, $\tau_{t}^{p}$ is the property tax rate, $\tau_{t}^{y}$ is the marginal income tax rate, $\delta_{t}$ is the combined maintenance and depreciation rate, $\lambda_{t}$ is the risk premium associated with housing, and $E_{t} G_{t+1}$ is expected capital gains. ${ }^{2}$ Equation (1) yields the standard result that in a frictionless market, prices should be high relative to rents when, among other things, interest rates are low and expected capital gains are high.

I define $C_{t}$ as the direct user cost of housing capital,

$$
C_{t}=\left(i_{t}+\tau_{t}^{p}\right)\left(1-\tau_{t}^{y}\right)+\delta_{t}
$$

That is, $C_{t}$ is the cost of housing excluding the risk premium and expected capital gains.

With a log-linearization similar to that used in the dividend ratio model for the stock market (Campbell, Lo, and MacKinlay, 1997), expected capital gains

\footnotetext{
${ }^{2}$ I ignore transaction costs; I assume that all local property taxes and interest payments are deductible from federal taxes and that houses are fully financed.
} 
can be approximated by

$$
E_{t} G_{t+1} \approx E_{t} \sum_{j=0}^{\infty} \rho^{j}\left[(1-\rho) \Delta R_{t+1+j}-C_{t+1+j}-\lambda_{t+1+j}\right],
$$

where $\rho$ depends on the levels of rents and prices around which the approximation is taken. ${ }^{3}$ Thus, prices should be high relative to rents when, among other things, expected future interest rates are low and expected future changes in rents are high.

Only a handful of papers deal directly with the question of how much the rent-price ratio helps predict future changes in rents and prices. Capozza and Seguin (1996) used decennial census data to examine how cross-sectional differences in the rent-price ratio among metropolitan areas in the United States are related to ten-year changes in prices in those areas. They tested whether the expected capital gains implicitly needed to support an area's rent-price ratio were closely related to actual capital gains. For each metropolitan area, Capozza and Seguin tried to control for the fact that rental and owner-occupied housing can differ in quality by using data on housing characteristics. They also decomposed the rent-price ratio into a component explained by local conditions and an unexplained residual. They found that the predictable part of the rentprice ratio was negatively related to subsequent price changes. That is, cities in which prices were high relative to rents for reasons associated with local conditions typically saw their relatively high prices justified by higher capital gains. They also found that the unpredictable part of the rent-price ratio, which they called the disequilibrium component, was positively related to subsequent price changes. That is, cities in which prices were high relative to rents for reasons not associated with local conditions had smaller realized capital gains.

Clark (1995) used an approach similar to that of Capozza and Seguin to test whether the rent-price ratio helped predict future changes in rents. He found that the rent-price ratio is significantly and negatively related to subsequent changes in rents. That is, prices appear to be higher in areas that subsequently have larger increases in rents.

These cross-sectional studies provide useful insights into the long-run predictive power of the rent-price ratio. However, the approach is less useful for examining the relationship between rents and house prices at a higher frequency.

\footnotetext{
${ }^{3}$ See Campbell, Lo, and MacKinlay (1997) for the derivations.
} 
Meese and Wallace (1994) used time-series data on prices, rents, and the cost of capital for Alameda and San Francisco counties to show that prices and rents are cointegrated. However, they did not examine how prices and rents adjust in the short run to reestablish the long-run equilibrium implied by the cointegrating relationship.

In related research, Blackley and Follain (1996) examined the link between rents and user cost. They found that increases in user cost are not fully matched by increases in rents and that rents adjust very slowly. However, they did not examine the predictive power of the rent-price ratio. Mankiw and Weil (1989) touched on the forecasting value of the rent-price ratio in a time-series setting, but they had a very short time series available to them. They found that the relationship between the rent-price ratio and future price growth was not statistically significant. Case and Shiller (1989) used high-frequency price and rent data to construct estimates of the return on housing but did not examine whether the rent-price ratio helps forecast future changes in rents and prices.

\section{The data}

\section{Definitions of the variables and measurement issues}

Four high-frequency measures of house prices are available for national-level studies of the housing market: (1) the new home price series (Census Bureau), (2) the existing home price series (National Association of Realtors), (3) the quality-adjusted price index for new homes sold (Census Bureau), and (4) the Conventional Mortgage House Price Index (Freddie Mac). ${ }^{4}$

The series for new and existing home prices are reported each month, but they are not adjusted for the types of homes sold and therefore cannot accurately measure the price of a home separately from its quality. The quality-adjusted price of new homes sold is based on hedonic regressions that include characteristics such as region of the country, whether the home is inside a metropolitan area, and the number of bedrooms (Census, 2004). However, the regressions do not include a measure of the location of the home within its fairly broad geographic designation. Because new homes are typically built on relatively cheap land, the price index cannot accurately reflect the land prices relevant for

\footnotetext{
${ }^{4}$ The Office of Federal Housing Enterprise Oversight publishes a house-price index similar to that of Freddie Mac. Both indexes are based on a weighted repeat-sales method.
} 
the existing stock of housing. ${ }^{5}$ Davis and Heathcote (2004) showed that land's share of the house price is quite large.

In this paper I use the Conventional Mortgage House Price Index (CMHPI) published by Freddie Mac. The index is based on price changes for homes that are resold or refinanced and is therefore not affected by changes in the composition of homes sold. In addition, the CMHPI sample excludes homes with jumbo, FHA, or VA mortgages.

According to several researchers, the repeat-sales methodology used in the CMHPI yields estimates of house-price growth that are upward biased because homes that change hands more frequently tend to have greater price appreciation (Gatzlaff and Haurin, 1997; Case, Pollakowski, and Wachter, 1997). Gatzlaff and Haurin show that the repeat-sales methodology created an upward bias of 0.33 percentage point per year using micro data for the Miami metropolitan area from 1971 to 1995 .

In related research, Dreiman and Pennington-Cross (2004) show that the standard methods for constructing a weighted repeat-sales price index are too restrictive. They show that the variance of price changes for individual properties are different for those properties that are either above or below the mean rate of appreciation and for properties that are in different price tiers. Dreiman and Pennington-Cross's more flexible specifications yielded price indexes with significantly smaller average annual increases than those from the standard approach; the biases ranged from 0.1 percentage point to 0.6 percentage point per year. ${ }^{6}$ Although I do not know how much the transactions biases of Gatzlaff and Haurin (1997) and the variance biases of Dreiman and Pennington-Cross (2004) overlap, the effects would seem unlikely to cancel each other. Still, I chose to be conservative and reduce the growth rate of the CMHPI only 0.3 percentage points per year. ${ }^{7}$

\footnotetext{
${ }^{5}$ For example, consider a monocentric city with fixed agricultural land prices, fixed construction costs, and a growing population (a setup along the lines of that in Henderson (1977)). The average price of all homes will increase steadily with population even though each wave of new homes sells for a constant price equal to the sum of the prices for agricultural land and the structure.

${ }^{6}$ They calculated alternative indexes for California, Georgia, Florida, Illinois, Kansas, North Carolina, Nevada, New York, Texas, and Washington. Anthony Pennington-Cross generously provided the data for the alternative price indexes for these ten states.

${ }^{7}$ The CMHPI ignores the effect of improvements to and deterioration of the samples houses. Data from the Bureau of Economic Analysis (BEA) on improvements to and physical depreci-
} 
My source for rent data is the index for tenants' rent from the Consumer Price Index (CPI). One could argue that the owners' equivalent rent series from the CPI is preferable because it is a measure of the rent that owners implicitly pay to themselves. As such, it is closer to housing "dividends" for owners. In contrast, tenants' rent measures rents paid by renters. Because rental units differ from owner-occupied units, they may not accurately reflect true alternatives for owners. ${ }^{8}$ The tenants' rent series has one crucial advantage: It is available for a much longer time series. Owners' equivalent rent is available from only 1983 ; the tenants' rent series begins well before the 1970:Q1 starting date for the house price data. The additional 13 years of data are vital for estimating the time-series relationship between prices and rents.

I adjusted the published rent data in two closely related ways. First, I boosted the growth rate of the index 0.3 percentage point per year prior to 1988 to try to match the adjustment that the Bureau of Labor Statistics (BLS) made to the published series beginning in 1988 to better reflect the aging of rental units (Moulton, 1997; Crone, Nakamura, and Voith, 2000 and 2004; Lebow and Rudd, 2003). Second, I increased the growth rate of the entire series an additional 0.2 percentage point per year during the entire sample period because several researchers have argued that BLS's age adjustment still does not adequately adjust for aging effects (Crone, Nakamura, and Voith, 2004; Lebow and Rudd, 2003).

I constructed an estimate of the direct user cost of housing capital on the basis of Equation (2). I used the 30-year fixed-rate mortgage rate relative to inflation expectations from the Philadelphia Federal Reserve Bank Survey, the property tax rate and marginal income tax rate (at twice the median income) used in the FRB/US model at the Federal Reserve Board (Reifschneider, Tetlow, and Williams, 1999), and the rate of depreciation on residential structures from the National Income and Product Accounts. ${ }^{9}$

ation of owner-occupied homes with one to four units indicate that improvements offset most of the effect of depreciation. In addition, because the BEA does not measure the implicit labor cost of do-it-yourself home improvements, the published data likely understate the actual pace of improvements.

${ }^{8}$ For example, the 2001 American Housing Survey showed that the proportion of dwellings that were detached single-family homes was 82 percent for owner-occupied homes but only 23 percent for rental homes.

${ }^{9}$ The depreciation rate on structures likely overstates the relevant depreciation rate because land, which is included in the price of a house, probably does not depreciate. 


\section{Rents, prices, and the direct user cost of housing capital}

From 1976:Q1 to 1979:Q4, real house prices relative to the deflator for personal consumption expenditures excluding food and energy (core PCE) rose an average of about 4-1/4 percent per year for a total gain of about 17 percent (Figure 1, top panel). Real house prices then went through a similar cycle from the mid-1980s through the mid-1990s before beginning a spectacular decade: From the end of 1994 to the end of 2003, they increased 45 percent. Over the entire period, real house prices increased a total of 63 percent, or 1-1/2 percent per year.

Rents relative to the core PCE deflator have been less volatile than house prices (Figure 1, bottom panel). They fell sharply in 1974 before starting a long and fairly steady rise that accelerated in the mid-1980s; by the end of 1986, real rents were up 12 percent from their trough. Real rents then stagnated for about 10 years before rising about 18 percent from the end of 1993 to the end of 2003 .

The log ratio of rents to prices shows a distinct trough in the late 1970s and a smaller one in the late 1980s (Figure 2, top panel). ${ }^{10}$ More recently, as house prices reached record highs relative to rents, the rent-price ratio reached a record low.

Simple augmented Dickey-Fuller tests (which are available from the author upon request) show that while we cannot reject the null hypothesis that prices and rents each have a unit root, we can reject that null for the rent-price ratio. In other words, prices and rents are cointegrated.

The direct cost of housing declined significantly from early 2000 through the end of 2003 to a level below the readings of most of the 1980s and 1990s (Figure 2, bottom panel). Even so, the cost was lower still in the late 1970s, when higher inflation and income tax rates helped keep the direct user cost of housing low even though nominal mortgage rates were high.

\section{Long-horizon relationships}

A scatterplot of the data from 1970 through 2003 with a fitted regression line shows that when prices have been high relative to rents (the rent-price ratio is low) rent increases during the subsequent three years have tended to be large,

\footnotetext{
${ }^{10}$ Because prices and rents are both measured as indexes, the absolute level of the ratio is meaningless. The average level of the log index is 97.8 .
} 
and that when house prices have been low relative to rents, subsequent rent increases have tended to be small (Figure 3, top panel). This result is consistent both with the theory and with Clark's (1995) results: Prices at least partially capitalize the present value of future rents, and relatively high prices therefore signal larger increases in rents.

A similar scatterplot (Figure 3, bottom panel) indicates that when prices are high relative to rents, subsequent price increases are small. This result appears to be consistent with the view taken by Leamer (2001) and others that a low rent-price ratio is a sign of overvaluation in the housing market that is subsequently, if slowly, eliminated. However, it does not appear to be consistent with the theory that high prices are typically supported by high capital gainsthe required capital gains do not seem to materialize.

The scatterplots provide suggestive evidence that when prices are high relative to rents, the two series move toward each other. However, the calculations on which this simple relationship is based ignore two potentially important econometric issues. First, the bivariate scatterplots do not include the effect of changes in the direct user cost of housing; the rent-price ratio may have little predictive power after such costs are included. Second, the quarterly observations of long-horizon differences are not independent of each other. In the following sections I address these shortcomings by using error-correction and long-horizon models to examine the predictive power of the rent-price ratio.

\section{An error-correction model of house prices and rents}

Error-correction models provide a simple way to examine the predictive power of the rent-price ratio. Let $y_{t}=\left(\log R_{t} \log P_{t}\right)^{\prime}$. The model is

$$
\Delta y_{t}=A_{0}(L) \Delta y_{t-1}+A_{1} y_{t-1}+A_{2}(L) x_{t-1}+\eta_{t}
$$

where $x_{t-1}$ includes other variables that can affect $\Delta y_{t}$. Because rents and prices are cointegrated, we can include their levels in the regression. ${ }^{11}$

I restricted $x_{t-1}$ to include levels and changes of the direct user cost of housing. I included the level of the direct cost because Equation (1) suggests

\footnotetext{
${ }^{11}$ The matrix of coefficients, $A_{1}$, can be thought of as the product of the cointegrating vector and a matrix of error-correction coefficients.
} 
that the levels of prices, rents, and the direct user cost should be related.

I calculated ordinary least squares estimates of two versions of Equation (4) using quarterly data from 1970:Q1 to 2003:Q4 and from 1970:Q1 to 2001:Q4. The first version included both the log rent-price ratio and the log of the direct cost of capital and the second version included only the log rent-price ratio. All the models include four lags of the changes in rents, prices, and the direct user cost, all in real terms. ${ }^{12}$ For the estimates based on the entire available sample, the signs of all the coefficients are consistent with Figure 3 (Table 1, first two columns). In particular, the negative coefficient on the lagged rent-price ratio in the rent equation and the positive coefficient on that ratio in the price equation imply the convergence of the rent and house price series. Because the absolute value of the coefficient on the lagged rent-price ratio is much larger in the price equation than it is in the rent equation, prices apparently correct more than rents do. In addition, the results suggest that when the level of the direct user cost is high, subsequent rent growth is large and subsequent price growth is small.

Unfortunately, all the point estimates are imprecisely estimated and not statistically significant at conventional levels. The data apparently do not permit identification of the nature of the error-correction process that maintains the long-run equilibrium implicit in the cointegrating relationship.

I also estimated the model with a time period that excludes the last two years of the sample (Table 1, last two columns). Price gains during these two omitted years far outstripped rent gains and drove the rent-price ratio down from levels that were already very low by historical standards (Figure 2, top panel). The results from the shorter period tell a qualitatively similar story: Rents and prices both appear to do some correcting, but prices appear to adjust more than rents. The estimated coefficient on the lagged rent-price ratio is larger when estimated on the shorter period, and is statistically significant in the price equation.

\footnotetext{
${ }^{12}$ I chose four lags based on the Schwartz criterion. The results are not sensitive to modest changes in the number of lags.
} 
Table 1

Error-Correction Models of Housing Prices

\begin{tabular}{|c|c|c|c|c|}
\hline & \multicolumn{2}{|c|}{ 1970:Q1 to 2003:Q4 } & \multicolumn{2}{|c|}{ 1970:Q1 to 2001:Q4 } \\
\hline & $\begin{array}{c}\text { rent } \\
\text { model }\end{array}$ & $\begin{array}{c}\text { price } \\
\text { model }\end{array}$ & $\begin{array}{c}\text { rent } \\
\text { model }\end{array}$ & $\begin{array}{c}\text { price } \\
\text { model }\end{array}$ \\
\hline \multicolumn{5}{|l|}{ Model 1} \\
\hline lagged rent-price ratio & $\begin{array}{l}-.028 \\
(.023)\end{array}$ & $\begin{array}{c}.093 \\
(.066)\end{array}$ & $\begin{array}{l}-.031 \\
(.026)\end{array}$ & $\begin{array}{l}.158^{*} \\
(.070)\end{array}$ \\
\hline lagged direct user cost & $\begin{array}{l}.005^{*} \\
(.002)\end{array}$ & $\begin{array}{l}-.005 \\
(.006)\end{array}$ & $\begin{array}{l}.004^{*} \\
(.002)\end{array}$ & $\begin{array}{l}-.005 \\
(.005)\end{array}$ \\
\hline \multicolumn{5}{|l|}{ Model 2} \\
\hline lagged rent-price ratio & $\begin{array}{l}-.013 \\
(.025)\end{array}$ & $\begin{array}{c}.079 \\
(.063)\end{array}$ & $\begin{array}{l}-.015 \\
(.026)\end{array}$ & $\begin{array}{l}.142^{*} \\
(.067)\end{array}$ \\
\hline
\end{tabular}

Notes: Standard errors are in parentheses. ${ }^{*}$ indicates a significance level of .05. All the models

include four lags of the changes in rents, prices, and the direct user cost, all in real terms.

Coefficients are expressed at an annual rate.

It is not surprising that excluding data from two years in which the rentprice ratio was very low and price gains far outstripped rent gains yielded larger estimated coefficients in the error-correction model. It is more difficult to know what to conclude. By extending the estimation to 2003:Q4, we are perhaps catching the long downturn in the rent-price ratio without catching the inevitable upturn. The small sample size may therefore make it impossible to get a precise estimate of the rate of error correction. Of course, the upturn may not occur - after all, the continuing decline in the rent-price ratio casts doubt on the premise that the ratio (as measured) is a useful predictor of prices.

Thus, although the error-correction model provides some support for the view that a low rent-price ratio is a sign of overvaluation in the housing market, the results are far from convincing. In the full sample, rents and prices appear to be cointegrated but the error-correction terms are not statistically significant in either equation; this combination suggests that using an error-correction model at a quarterly frequency may be "asking" too much of the data. 


\section{$5 \quad$ A long-horizon model of house prices and rents}

\section{Method}

My examination of the rent-price ratio as a predictor of changes in rents and prices at horizons longer than one quarter closely follows that of Campbell and Shiller's (2001) examination of how well the dividend-price ratio predicts stock dividends and prices and Mark's (1995) examination of how well a nation's money stock and domestic income predict exchange rates. ${ }^{13}$ Like Campbell and Shiller (2001), and, indeed, like Capozza and Seguin (1996) and Clark (1995), I do not conduct a strict test of the present-value model in Equations (1) and (3). Rather, these equations serve as the motivation for the common use of the rent-price ratio as a measure of valuation in the housing market.

The following equations form the heart of my long-horizon empirical strategy:

$$
\begin{aligned}
& r_{t+12}-r_{t}=a_{0}+a_{1}\left(r_{t}-p_{t}\right)+a_{2} c_{t}+u_{t} \\
& p_{t+12}-p_{t}=b_{0}+b_{1}\left(r_{t}-p_{t}\right)+b_{2} c_{t}+v_{t}
\end{aligned}
$$

where lower-case letters denote $\log$ values and $t$ indexes quarters, so that $t+12$ indicates $t$ plus three years.

The coefficients $a_{1}$ and $b_{1}$ have, at first glance, simple interpretations. They show how changes in rents and prices over a three-year horizon are related to the rent-price ratio at the beginning of the three-year period (after controlling for the effect of $c_{t}$ ). It is tempting to employ the language commonly used to describe error-correction models: one would say that the signs and magnitudes of $a_{1}$ and $b_{1}$ tell us whether, and by how much, rents "correct" to prices and prices "correct" to rents. However, true error-correction models typically include lagged values of the difference in the variable of interest. In this case, one would include measures of $r_{t+11}-r_{t-1}$ and $p_{t+11}-p_{t-1}$ and their lags on the right side of the regressions. A long-horizon model, by definition, cannot include these terms because to do so would effectively make it an error-correction model. Excluding these variables induces the statistical problems associated with autocorrelated residuals in models with lagged dependent variables. The following example illustrates this point.

\footnotetext{
${ }^{13}$ Hodrick (1992) and Fama and French (1988) are earlier antecedents.
} 
Suppose that $r_{t}$ and $p_{t}$ are generated by the following processes:

$$
\begin{aligned}
r_{t} & =p_{t}+\epsilon_{r, t} \\
\Delta p_{t} & =\alpha \Delta p_{t-1}+\epsilon_{p, t}
\end{aligned}
$$

where

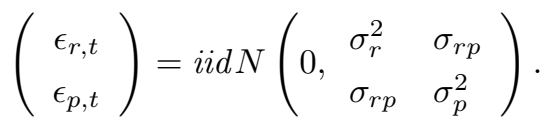

Note that rents and prices are cointegrated by assumption (because $\epsilon_{r, t}$ is stationary) but that rents do all the correcting. That is, the level of $p_{t}$ does not react to the level of $r_{t}$, but the level of $r_{t}$ does react to the level of $p_{t}$.

Suppose that instead of the three-year horizon used in Equations (5) and (6), we were interested in a model of horizon $s$. Then Equations (7) and (8) imply that

$$
\begin{aligned}
r_{t+s}-r_{t} & =p_{t+s}-p_{t}+\epsilon_{r, t+s}-\epsilon_{r, t} \\
p_{t+s}-p_{t} & =\sum_{j=1}^{s} \sum_{k=0}^{\infty} \alpha^{k} \epsilon_{p, t+j-k} .
\end{aligned}
$$

Ordinary least squares estimation of the long-horizon models would asymptotically yield the following estimates:

$$
\begin{aligned}
& \hat{a}_{1}=\frac{\alpha\left(1-\alpha^{s}\right)}{1-\alpha} \sigma_{r p}-1 \\
& \hat{b}_{1}=\frac{\alpha\left(1-\alpha^{s}\right)}{1-\alpha} \sigma_{r p} .
\end{aligned}
$$

Thus, the null hypothesis that "rents do all the correcting" does not imply that $b_{1}=0$. The term $\frac{\alpha\left(1-\alpha^{s}\right)}{1-\alpha} \sigma_{r p}$ captures the fact that shocks to the rent-price ratio can be correlated with shocks to the change in log real prices. Any autocorrelation in the change in prices can therefore induce a correlation between the rent-price ratio and long-horizon differences in prices.

Several additional points merit mention. First, $b_{1}$ will equal zero under the null hypothesis if $\alpha=0$. Thus the approaches of Mark (1995) and Campbell and Shiller (2001), which assume $\alpha=0$, are valid if that assumption holds. Second, more complicated processes for rents and prices yield more complicated bias terms. Third, because

$$
\operatorname{cov}\left(p_{t+1}-p_{t}, r_{t}-p_{t} \mid p_{t}-p_{t-1}\right)=\operatorname{cov}\left(\epsilon_{p, t+1}, \epsilon_{r, t}\right)=0,
$$

error-correction models do not suffer from this problem. 
I use a bootstrap approach to correct for the biases inherent in the longhorizon approach. My approach follows closely that of Campbell and Shiller (2001) and Mark (1995). I built small- and large-sample bootstrap distributions using restricted autoregressions that, by construction, match the null hypothesis that rents do all the correcting. Let $z_{t}=r_{t}-p_{t}$. The bootstrap distributions are based on

$$
\begin{aligned}
\Delta z_{t} & =\gamma_{0}+\gamma_{1} z_{t-1}+\sum_{j=1}^{4} \gamma_{2, j} \Delta z_{t-j}+\epsilon_{r, t} \\
\Delta p_{t} & =\alpha_{0}+\sum_{j=0}^{J} \alpha_{1, j} \Delta p_{t-j}+\epsilon_{p, t} .
\end{aligned}
$$

Equation (15) ensures that rents and prices are cointegrated; Equation (16) ensures that prices have a unit root but that the level of rents does not affect the level of prices; rents do all the correcting. ${ }^{14}$

I estimated Equation (15) using four lags of $\Delta z_{t-1-j}$. I based the lag length on the Schwartz criterion. I found that $\hat{\gamma}_{1}=-.05$ with an Augmented Dickey Fuller test statistic of 3.45, large enough to reject the hypothesis of a unit root; indeed, this is the equation to which I referred in Section 3 to establish the stationarity of the rent-price ratio. The four versions of Equation (16) that I estimated were determined by letting $J$ equal 0,1 , 4, and 8 quarters (Appendix Table A.1).

Let $\hat{\epsilon}_{t}=\left(\hat{\epsilon}_{r, t}, \hat{\epsilon}_{p, t}\right)^{\prime}$ and $\hat{\gamma}_{0}, \hat{\gamma}_{1}, \hat{\gamma}_{2, j}, \hat{\alpha}_{0}, \hat{\alpha}_{1, j}$ be the estimated residuals and coefficients. I constructed the large-sample bootstrap distribution of $\hat{a}_{1}$ and $\hat{b}_{1}$ by running 10,000 replications of the following procedure, indexed by $i$ :

1. Let $T=4,000$. Draw with replacement $T+100$ values from $\hat{\epsilon}_{t}$; call them $\left\{\epsilon_{t}^{i}\right\}_{t=1}^{T+100}$.

2. With sample means for initial values, generate sequences of artificial observations using

$$
\begin{aligned}
\Delta z_{t}^{i} & =\hat{\gamma}_{0}+\hat{\gamma}_{1} z_{t-1}+\sum_{j=1}^{4} \hat{\gamma}_{2, j} \Delta z_{t-j}+\epsilon_{r, t}^{i} \\
\Delta p_{t}^{i} & =\hat{\alpha}_{0} \sum_{j=0}^{J} \hat{\alpha}_{1, j} \Delta p_{t-j}+\epsilon_{p, t}^{i} .
\end{aligned}
$$

\footnotetext{
${ }^{14} \mathrm{As}$ an alternative, one could impose a restriction consistent with the null hypothesis that prices do all the correcting. However, because shocks to the rent-price ratio are not highly correlated with shocks to rents, the bias under this null is small.
} 
3. Construct the levels of $p_{t}^{i}$ from Equation (18) using the sample mean as the initial value, and the levels of $r_{t}^{i}$ from $z_{t}^{i}+p_{t}^{i}$.

4. Drop the first 100 observations, construct $p_{t+12}^{i}-p_{t}^{i}, r_{t+12}^{i}-r_{t}^{i}$, and regress them on $z_{t}^{i}$. Keep the estimated coefficients $\hat{a}_{1}^{i}$ and $\hat{b}_{1}^{i}$.

The mean values of $\hat{a}_{1}^{i}$ and $\hat{b}_{1}^{i}$ provide estimates of the values of $a_{1}$ and $b_{1}$ under the null hypothesis implied by Equations (17) and (18). Call them $a_{1}^{0}$ and $b_{1}^{0}$.

I conducted a similar procedure to generate small-sample distributions for $\hat{a}_{1}$ and $\hat{b}_{1}$ in which I set $T=124$ to match my actual sample size. Using 100, 000 replications of the above procedure, indexed by $k$, I collected the small-sample t-statistics defined as

$$
\begin{aligned}
& t\left(\hat{a}_{1}\right)=\left(\hat{a}_{1}^{k}-a_{1}^{0}\right) / \hat{\sigma}_{a_{1}}^{k} \\
& t\left(\hat{b}_{1}\right)=\left(\hat{b}_{1}^{k}-b_{1}^{0}\right) / \hat{\sigma}_{b_{1}}^{k} .
\end{aligned}
$$

\section{Results}

The results from regressions of the three-year-ahead changes in real rents and prices on the log rent-price ratio and on the log of the direct user cost of housing capital are qualitatively similar to those from the error-correction models (Table 2).

The results imply that for each 10 percentage point difference between rents and prices, the change in real rents is 0.61 percentage point less per year, and the change in real prices is on average 1.69 percentage points more per year, during the subsequent three years (Table 2, columns 1 and 3, which correspond to the regression lines in Figure 3). Thus, periods in which prices are high relative to rents are typically followed by periods of relatively larger changes in rents and relatively smaller changes in prices and the effect on prices is more than twice as large.

Inclusion of the direct user cost of housing capital does not significantly affect the estimated coefficients on the rent-price ratio in either model (Table 1, columns 2 and 4). The direct user cost of housing capital is positively related to future rent changes and negatively related to future price changes. Thus periods in which the direct user cost of housing capital is higher are typically followed by periods in which the change in rents is larger and the change in prices is 
Table 2

Long-Horizon Models of the Change in Rents and Prices

\begin{tabular}{|c|c|c|c|c|}
\hline & \multicolumn{2}{|c|}{ Rent Model } & \multicolumn{2}{|c|}{ Price Model } \\
\hline & 1 & 2 & 3 & 4 \\
\hline \multirow[t]{2}{*}{$\log$ rent-price ratio } & -.061 & -.083 & .169 & .174 \\
\hline & $(.017)$ & $(.015)$ & $(.038)$ & $(.039)$ \\
\hline \multirow[t]{2}{*}{ direct user cost } & - & .030 & - & -0.007 \\
\hline & & $(.004)$ & & $(.011)$ \\
\hline R-squared & .09 & .33 & .14 & .14 \\
\hline
\end{tabular}

smaller. This result should not be surprising to those who think that rents and prices adjust slowly to shocks. However, more important for present purposes is the fact that including the level of the direct user cost does not appear to affect the relationship between the rent-price ratio and subsequent changes in rents and prices. Given the insensitivity of the results to the inclusion of the direct cost of housing capital, I focus the bootstrap exercise on the simpler models shown in columns 1 and 3 .

Table 3 contains the results of the bootstrap exercise. The first column of the table simply re-displays the coefficient estimates from columns 1 and 3 of Table 2 . The remaining columns contain the values of the coefficients $a_{1}$ and $b_{1}$ under the null hypotheses that rents and prices are cointegrated, that rents do all the correcting, and that the change in the log of real rents follows either a unit root or an autoregressive process with 1, 4, or 8 lags; the log of real rents is a random walk with drift if there are zero lags. I calculated these null values using the large-sample bootstrap described above. The table also displays the p-values of the tests that the estimated coefficients are different from the null produced by the large-sample bootstrap; the p-values are based on the smallsample bootstrap described above.

The results of the large-sample bootstrap described above for the null hypothesis for $a_{1}$ (the rent model) imply that for each 10 percentage point differ- 
ence between rents and prices, the annualized change in real rents is 2.58 percentage points to 4.55 percentage points smaller during the subsequent three years (Table 3 ). Although the actual estimated value for $a_{1},-.061$, indicates that periods of relatively high prices are typically followed by periods in which the change in rents is relatively large, the effect is quite small compared with what one would expect if rents did all the correcting. Indeed, regardless of the presumed time-series properties of prices, the small-sample bootstrapped p-values for $a_{1}$ indicate that the estimated coefficient is in the far right tail of the small-sample bootstrap distributions, suggesting that we should reject the null hypothesis that rents do all the correcting.

In the price model, the null hypothesis that rents do all the correcting implies a negative estimate of $b_{1}$ as long as prices follow a unit root rather that a strict random walk. Recall from Equation (13) that the bias term depends on the covariance of the shocks to $\Delta p_{t}$ and $z_{t}$ and the time-series properties of $\Delta p_{t}$.

The actual estimate for $b_{1}, .169$, indicates that price growth is slower in years that follow periods of low rent-price ratios than one would expect if prices did not correct to rents. For example, under the null hypothesis that prices follow a random walk, one would expect $b_{1}$ to equal zero. However, although the actual estimate is above the null's value, the small-sample p-value of .14 indicates that this event is not rare enough to reject the null hypothesis at conventional levels of significance. The assumption that changes in house prices follow an AR(1) process yields a similar results. However, under the more reasonable null hypothesis that changes in prices are persistent (with lags of 4 quarters or 8 quarters), the p-values are low enough to reject the null hypothesus that rents do all the correcting. Thus, the long-horizon regression results and bootstrap Monte Carlos suggest that periods in which prices are high relative to rents are typically followed by periods in which changes in real rents are larger than usual and changes in real prices are smaller than usual. 
Table 3

Bootstrapped Significance Level

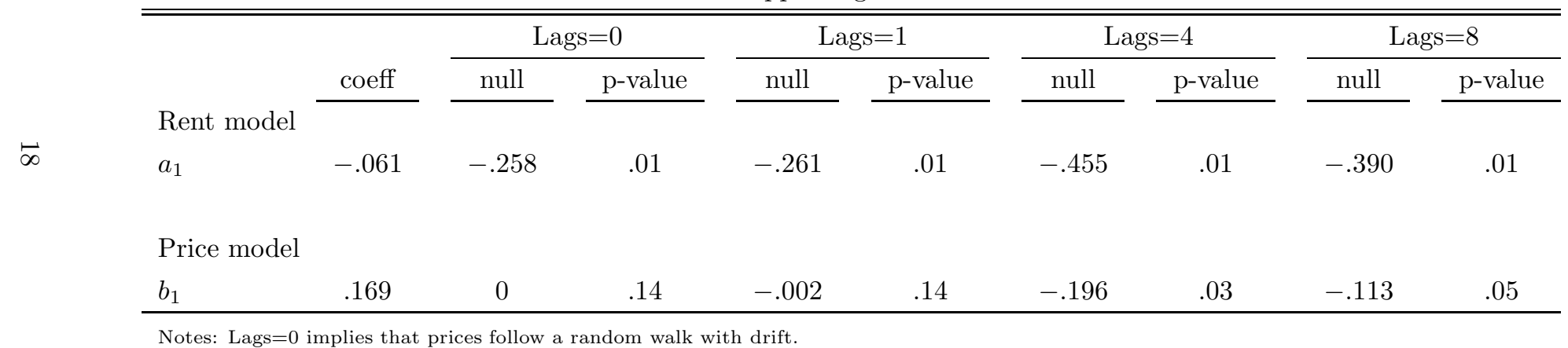

Notes: Lags $=0$ implies that prices follow a random walk with drift. 


\section{Summary}

The evidence I presented in this paper suggests that when house prices are high relative to rents, subsequent changes in real rents are larger than usual and subsequent changes in real house prices are smaller than usual. The conclusion is based on the results from three related analyses in which I measured house prices using Freddie Mac's Conventional Mortgage House Price Index and rents using the CPI index for tenants' rent.

In the first analysis, simple regessions of the data from the house-price and rent series suggested that rents and prices tend to correct back to each other over three-year horizons. But the regressions do not include the effects of changes in the direct user cost of housing nor do they account for the interdependence of quarterly observations over a long period. In the second analysis, I showed that standard error-correction models corroborated the evidence from the initial regressions, but were not definitive: Although rents and prices appear to be cointegrated, and although the point estimates from the error-correction models show that rents and prices both correct toward each other, none of the coefficient estimates of the speed of correction were statistically significant when I used all the available data from 1970:Q1 to 2003:Q4.

The third analysis provided the most conclusive evidence that house prices correct back to rents. I used a bootstrap procedure to construct artificial data that conform to the null hypothesis that rents and prices are cointegrated, but that rents do all the correcting. I then used these artificial data with a long-horizon regression model to examine how the rent-price ratio is related to changes to real rents and prices over three-year horizons. Under the null hypothesis, we would expect rents to "correct" much faster than they do in the actual data. In addition, we would expect to find a negative correlation between the rent-price ratio and the change in real house prices instead of the positive correlation apparent in the data. These results provide evidence against the null that rents do all the correcting and that prices do none.

Because a low rent-price ratio has been a harbinger of sluggish price growth since 1970, it seems reasonable to treat the rent-price ratio as a measure of valuation in the housing market. Indeed, one might be tempted to cite the currently low level of the rent-price ratio as a sign that we are in a houseprice "bubble." However, several important caveats argue against such a strong 
conclusion and in favor of further research.

First, the data I used in this paper are imperfect. The greatest concern is that neither the rent data nor the house-price data accurately measure rent and price changes. In this paper, I used the latest results from the literature on the measurement of house prices and rent to adjust the published data. However, we still need better measures of house prices and rents to fully understand their relationship.

Second, the motivating model in this paper, in which rents equal the textbook version of user cost, is too simple. For instance, the analysis in this paper essentially ignores potential transactions costs and the risks involved in renting and owning (Sinai and Souleles, 2003).

Third, even if the rent-price ratio can be thought of as a measure of valuation in the housing market, we should not expect it to be a precise indicator of if, when, and by how much house prices will change direction. Asset price movements are notoriously hard to predict; the housing market is no exception. 


\section{Appendix Table A.1}

Autoregressions for Changes in Real House Prices

\begin{tabular}{|c|c|c|c|}
\hline & \multicolumn{3}{|c|}{ Number of Lags } \\
\hline & 1 & 4 & 8 \\
\hline \multirow[t]{2}{*}{$\Delta p_{t-1}$} & 0.204 & 0.167 & 0.414 \\
\hline & $(.091)$ & $(.081)$ & $(.096)$ \\
\hline \multirow[t]{2}{*}{$\Delta p_{t-2}$} & - & 0.126 & 0.132 \\
\hline & & $(.083)$ & $(.101)$ \\
\hline \multirow[t]{2}{*}{$\Delta p_{t-3}$} & - & -0.059 & 0.101 \\
\hline & & $(.079)$ & $(.092)$ \\
\hline \multirow{2}{*}{$\Delta p_{t-4}$} & - & 0.501 & 0.277 \\
\hline & & $(.078)$ & $(.084)$ \\
\hline \multirow[t]{2}{*}{$\Delta p_{t-5}$} & - & - & -0.216 \\
\hline & & & $(.079)$ \\
\hline \multirow[t]{2}{*}{$\Delta p_{t-6}$} & - & - & -0.008 \\
\hline & & & $(.082)$ \\
\hline \multirow[t]{2}{*}{$\Delta p_{t-7}$} & - & - & -0.190 \\
\hline & & & $(.082)$ \\
\hline \multirow[t]{2}{*}{$\Delta p_{t-8}$} & - & - & 0.197 \\
\hline & & & $(.080)$ \\
\hline R-squared & .156 & .415 & .505 \\
\hline
\end{tabular}

Notes: OLS standard errors are in parentheses. 


\section{References}

[1] American Housing Survery for the United States: 2001 U.S. Department of Commerce, 2001

[2] Blackley, Dixie M. and Follain, James R. (1996) "In Search of Empirical Evidence that Links Rent and User Cost." Regional Science and Urban Economics 26:409-431.

[3] Calhoun, Charles, A. (1996). "OFHEO House Price Indexes: HPI Technical Description." Office of Federal Housing Enterprise Oversight. http://www.ofheo.gov/house/download.html.

[4] Campbell, Lo, and MacKinlay. (1997). The econometrics of financial markets Princeton, N.J. : Princeton University Press, 1997.

[5] Campbell, John Y. and Shiller, Robert J. (1988). "Stock Prices, Earnings, and Expected Dividends", Journal of Finance, 43, 661-676.

[6] Campbell, John Y. and Shiller, Robert J. (2001). "Valuation Ratios and the Long-Run Stock Market Outlook: An Update", NBER Working Paper W8221.

[7] Capozza, Dennis R. and Seguin, Paul J. (1996). "Expectations, efficiency, and euphoria in the housing market", Regional Science and Urban Economics 26, 369-385.

[8] Case, Bradford and Henry O. Pollakowski and Susan M. Wachter. (1997). "Frequency of Transaction and House Price Modeling", Journal of Real Estate Economics, 14, 173-187.

[9] Case, Karl E.; Shiller, Robert J. (1989). "The Efficiency of the Market for Single-Family Homes", American Economic Review, 79, 125-37.

[10] Clark, Todd E. (1995). "Rents and Prices of Housing Across Areas of the United States: A Cross-Section Examination of the Present Value Model," Regional Science and Urban Economics 25:237-247.

[11] Crone, Theodore, Nakamura, Leonard, and Voith, Richard. (2000). "Measuring Housing Services Inflation," Journal of Economic and Social Measurement, 26:153-171. 
[12] Crone, Theodore, Nakamura, Leonard, and Voith, Richard. (2004). "Hedonic Estimates of the Cost of Housing Services: Rental and OwnerOccupied Units," Presented at the International Conference on Index Number Theory and the Measurement of Prices and Productivity, June, 2004, Vancouver, British Columbia.

[13] Davis, Morris and Jonathan Heathcote. (2004). "The Price and Quantity of Residential Land in the United States", Federal Reserve Board FEDS paper 2004-37

[14] Dreiman, Michelle H. and Pennington-Cross, Anthony. (2004). "Alternative Methods of Increasing the Precision of Weighted Repeat Sales House Prices Indices." Journal of Real Estate Finance and Economics, 28(4):299317.

[15] Fama, Eugene F. and French, Kenneth R (1988). "Dividend Yields and Expected Stock Returns." Journal of Financial Economic, 22(1):3-25.

[16] Gatzlaff, Dean H. and Donald R. Haurin. (1997). "Sample Selection Bias and Repeat-Sales Index Estimates", Journal of Real Estate Economics, 14, 33-50.

[17] Henderson, J. V. (1977) Economic Theory and the Cities New York: Academic Press, 1977.

[18] Hodrick, Robert J. (1992). "Dividend Yields and Expected Stock Returns: Alternative Procedures for Inference and Measurement." review of Financial Studies, 5(3):357-386.

[19] Leamer, Edward E. (2002). "Bubble Trouble? Your Home Has a P/E Ratio Too", UCLA Anderson Forecast, June 2002.

[20] Mankiw, N. Gregory and David N. Weil. (1989). "The baby boom, the baby bust, and the housing market", Regional Science and Urban Economics 19, 235-258.

[21] Mark, Nelson C. (1995). "Exchange Rates and Fundamentals: Evidence on Long-Horizon Predictability?", American Economic Review 85, 201218. 
[22] Lebow, David and Jeremy Rudd. (2003). "Measurement Error in the Consumer Price Index: Where Do We Stand?", Journal of Economic Literature, 41, 159-201.

[23] Reifschneider, D., Tetlow, R., Williams, J. (1999) "Aggregate disturbances, monetary policy, and the macroeconomy: The FRB/US perspective" Federal Reserve Bulletin, 85, Issue 1, 1-19.

[24] Sinai, Todd and Nicholas S. Souleles. (2003). "Owner-Occupied Housing as a Hedge against Rent Risk", NBER working paper 9462. 


\section{Figure 1 \\ Real House Prices and Rents \\ (1970:Q1 to 2003:Q4)}

\section{Real house prices}

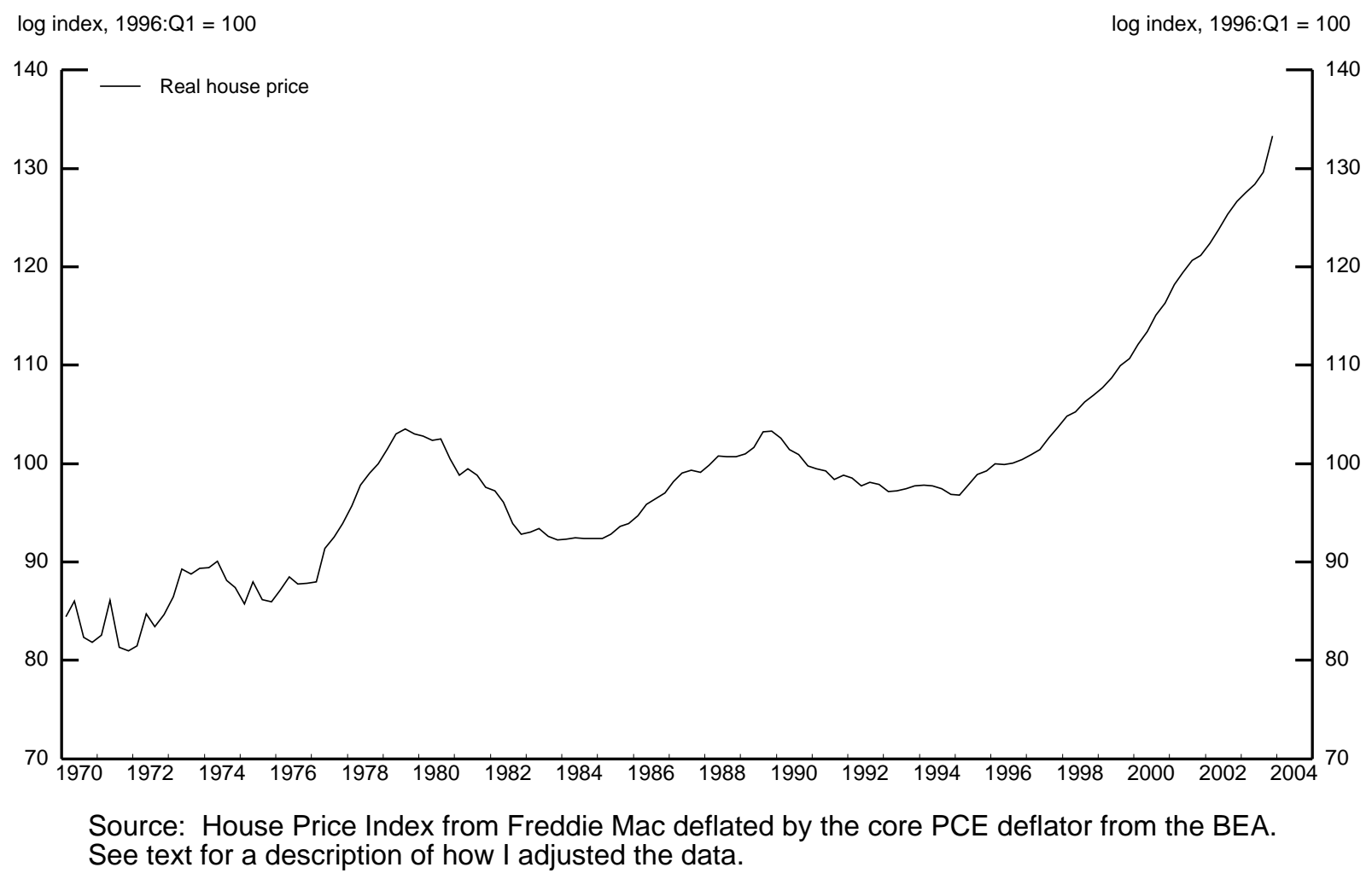

\section{Real rents}

log index, 1996:Q1 = 100

$\log$ index, 1996:Q1 = 100

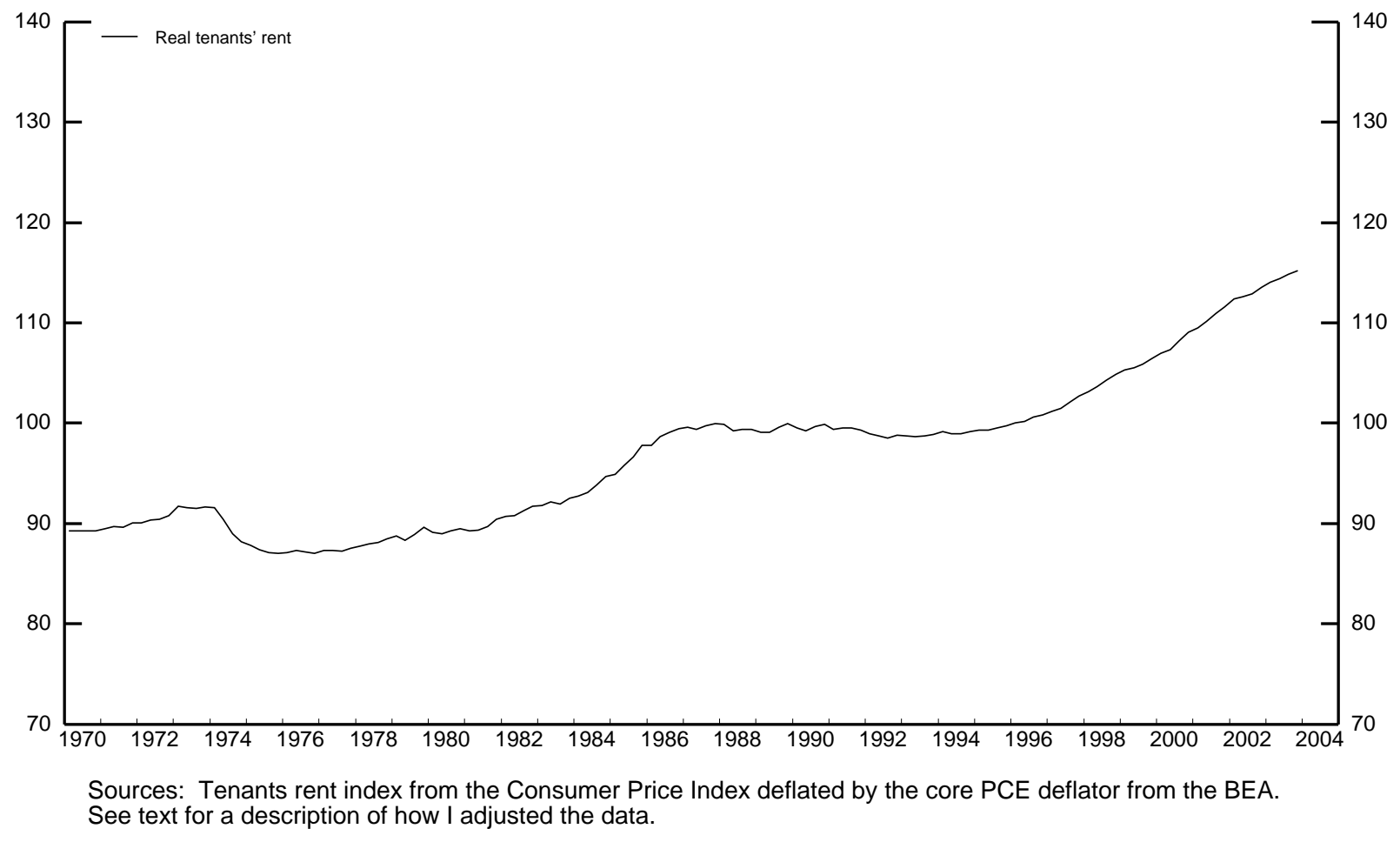


Figure 2

The log rent-price ratio and the direct user cost of housing capital

(1970:Q1 to 2003:Q4)

\section{Rent-price ratio}

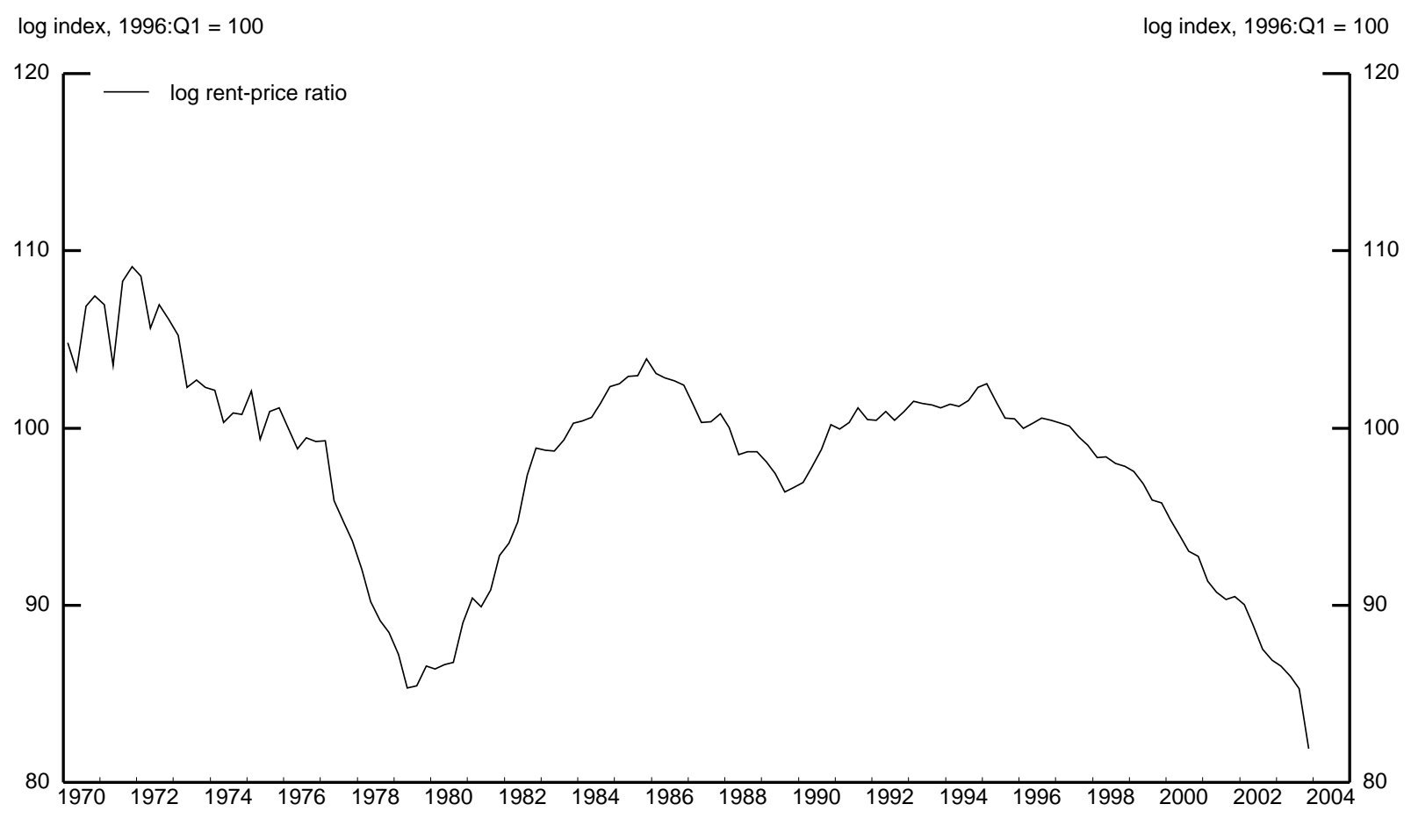

Sources: Same as Figure 1. See text for a description of how I adjusted the data.

\section{User cost of capital}

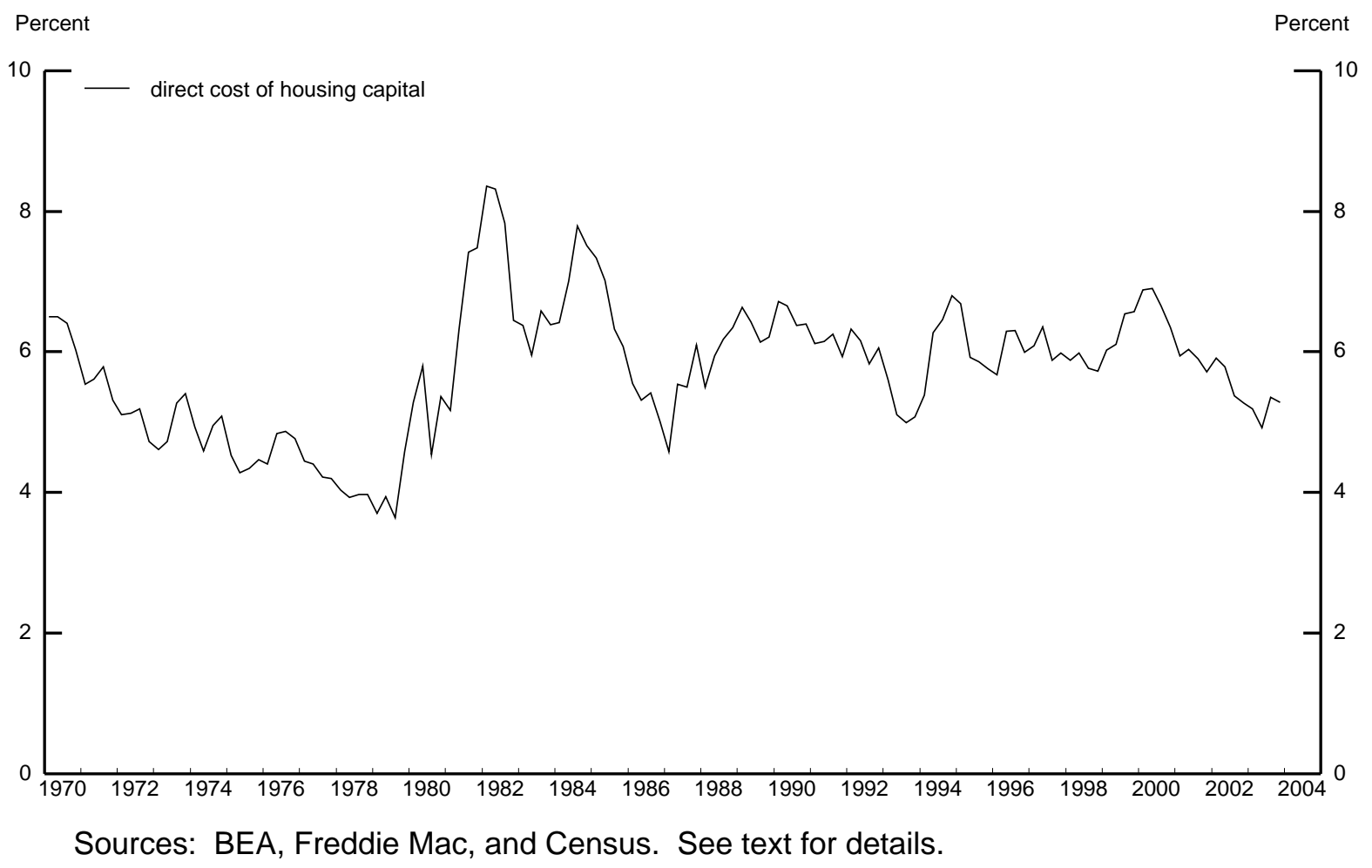


Figure 3

The Log Rent-Price Ratio and Subsequent Changes in Rents and Prices

Three Years Ahead

(1970:Q1 to 2003:Q4)
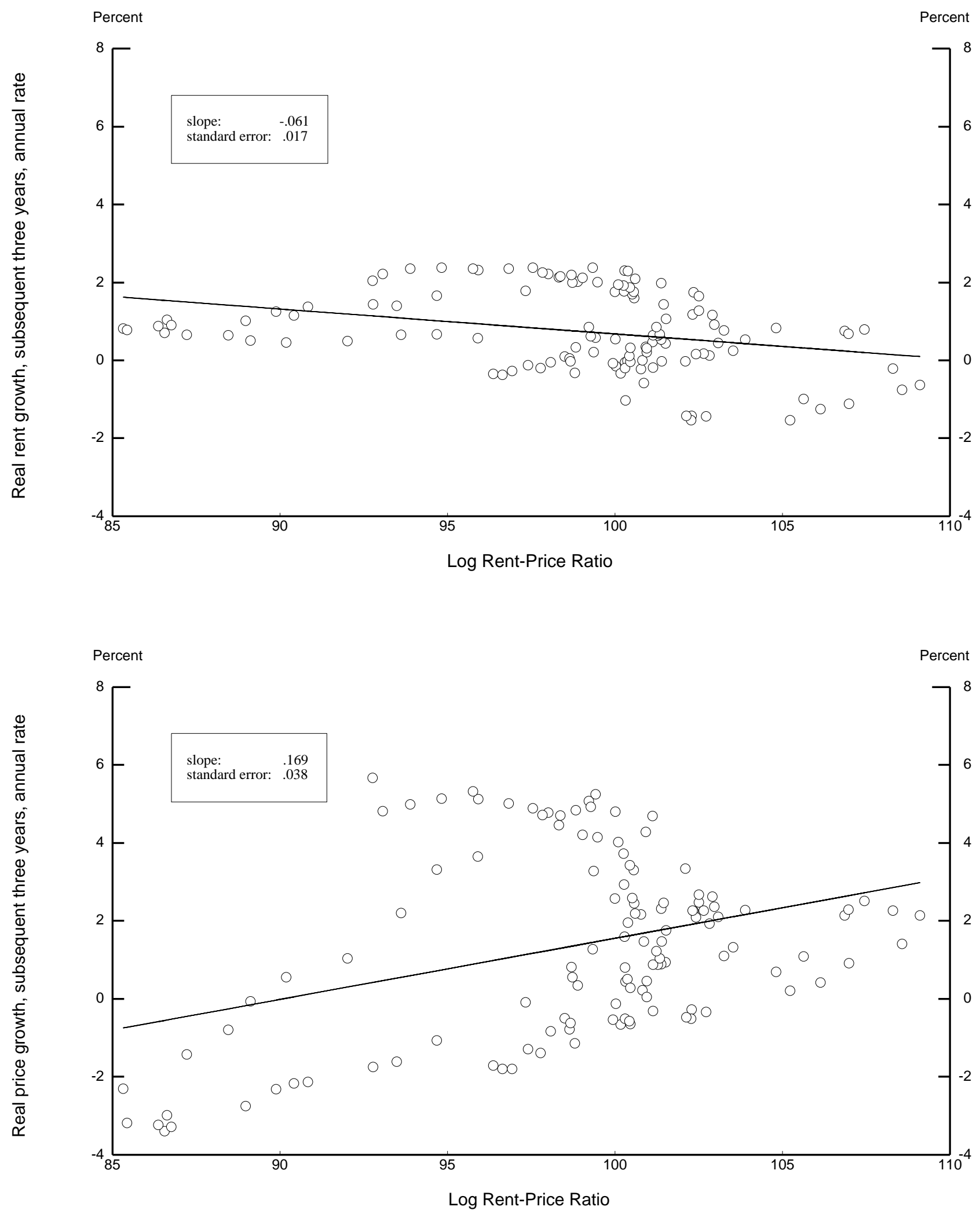